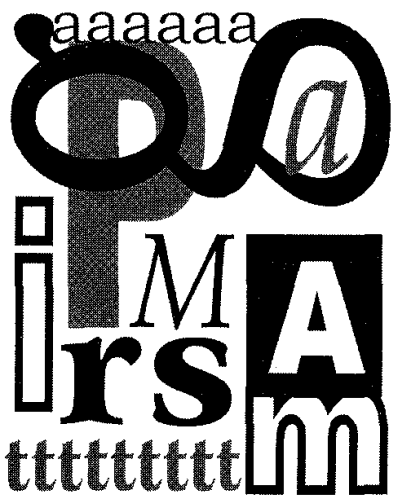

\title{
El Quijote y las locuras de la crítica*
}

\author{
María Rosa Palazón
}

$Y$ sus males, ¿quién los cura?/Locura./De ese modo, no es cordura/querer curar la pasión/cuando los remedios son/muerte, mudanza y locura. Don Quijote I, XXVII, p. 329.

os locos cuerdos contra los cuerdos locos. Calvino y Lutero, embestidos de
solemnidad, no soportaron el inteligente tono humorista con que Erasmo trató asuntos religiosos y un aplastante dominio que minimiza y excluye al otro, al rebelde, mediante el ardid de llamarlo loco, como le sucedió a aquel graduado en cánones cuyos parientes, en contubernio con el rector de la Casa de Locos de Sevilla, lo encerraron en ella con el objeto de esquilmarle su hacienda (Don Quijote, II, pról.). El Bachiller Sansón Carrasco siempre quiso volver al redil a la oveja extraviada que se llamó a sí mismo Don Quijote de la Mancha, a pesar de que Cide Hamete Benengeli dice bien que tan locos son los burladores como los burlados (II, LXX). También Lope de Vega se congratuló de que un individuo volviera a "la razón" en el Loco cuerdo. Miguel de Cervantes, en franca rebelión, tuvo una notable simpatía por los desadaptados a un statu quo, o Edad de Hierro (II, XX) donde crujen los damascos y brocados, triunfando la pereza sobre el diligente trabajo creativo; el vicio sobre la virtud; las presunciones y la arrogancia sobre la valentía o el atrevimiento de los luchadores por la justicia (II, XVII).

Mi loca interpretación. Los intrigantes perversos no admiten reglas morales y obstinadamente niegan la diferencia para imponerse, a cambio de una raquítica cuota de poder, mediante un inmoral pragmatismo que, contradiciendo el impera-

*Ponencia presentada en la Mesa Redonda "Don Miguel de Cervantes y Saavedra y un paseo por la crítica y la literatura mexicana", organizada por el CEPE con motivo del 450 aniversario de la muerte de Cervantes, el 13 de noviembre de 1997. 
tivo kantiano, expresado en la Fundamentación a la crítica de las costumbres, considera al otro siempre únicamente como un medio y no como un fin, lo que en palabras de Cervantes se resume a que sin buena intención van errados los medios y los fines (I, L), y que Ramiro de Maeztu explica en estas frases: "el predominio de un ideal coordina los impulsos y ajusta al mismo tiempo los medios y los fines." (p.21) Luego, no me parece acertada la observación de Michel Foucault de que nuestro personaje, moral por excelencia, niega al tú en cuanto diferente en el juego de "lo Mismo y de lo Otro" (p.56), o síntoma inequívoco del poder de dominio que, llegando a un extremo, coloca al individuo en un delirio que redundantemente repite el mismo mensaje, haciendo girar el mundo alrededor de su ego herido. Ésta es la locura que Erasmo atribuyó a las Furias, con cabellera de serpientes, es decir, con petrificante mirada psicótica, que sube de los infiernos cargada de dolor y sentimientos de culpa.

Afortunadamente, con excepción de los fuertemente perversos o perdidos en la isla solitaria de su enorme dolor, los demás tenemos una loca parte de nosotros que entiende la razón de la sin razón, porque casi siempre ser loco únicamente significa estar fuera del uso de otros hombres (II, XIX). Esta parte nuestra está hastiada de la depravación que justifica el engaño como instrumento para la obtención de cosas que, a largo plazo, no benefician a nadie. Estamos hartos de acordarnos a unas normas de convivencia al tenor de la mentira y la adulación que, según la descriptiva imagen erasmista, pasa a los demás la mano por el lomo, no de manera inofensiva y mansa, sino llena de perfidia e interés, y de la cual fue enemigo el hidalgo manchego (I, XXIX). Adular envilece mientras que la autoestima, el amor propio o satisfacción de uno mismo, nos fortalece, porque únicamente es ruin quien por ruin se tiene (I, XXI) y acepta los aspectos sociales enfermizos.

A nuestra parte loca o desadaptada le gusta la sinceridad, ser firmes en una acción conforme a una palabra sin dobleces ni sofismas (I, XXV), contradiciendo al mentiroso contumaz que obra en sentido opuesto a lo que predica - su diz que fe sin actos que la hagan fuerte- y que levanta falsos testimonios. Un mentiroso no está adomado como Don Quijote con las virtudes teologales y cardinales, no es valiente y liberal en sus obras, jamás acomete los peligros, ni honesto en sus palabras, esto es, no mantiene la verdad, la suya, aunque le cueste la vida (II, XVIII).

También nuestra locura está fastidiada de que tengamos que acudir a toda clase de sesudos ardides en previsión de un resultado que siempre es insatisfactorio, perdiendo el gozo del actuar mismo, del instante presente que es la vida. Deseamos que la cotidianeidad se llene de grandes fazañas y peligrosas aventuras (I, XIII) que se sucedan unas a otras en tropel (II, XVII). Deseamos ser un individuo juguetón o creativo, dialogante y veraz, o sea un anormal o desadaptado loco cuerdo. 
Porque a ratos creemos que el buen corazón quebranta mala ventura (II, X), anhelamos meter ruido en el insano orden de quienes compiten, recelan y envidian, obligándonos a defendernos de sus triquiñuelas. Cómo nos encanta la espontáneamente bella personalidad de aquel generoso y paciente cincuentón manchego que imitó a los buenos, fue azote de los malos y enemigo de los ruines, sin dejar de ser comedido, excepto cuando interpretó las circunstancias específicas bajo indicadores de las novelas de caballería (I, XLIX). Él nos arroba porque nunca pensó mal del prójimo y, por lo mismo, prefirió creer que hay encantadores que truecan y mudan los hechos y no que hubo maldad en sus allegados. Estos deslices se debieron a que quien no agravia conscientemente a nadie, no puede ser agraviado (II, XXX). También esta clase de alma noble y generosa (I, XV y XXI) siempre perdona a ricos y a pobres, hidalgos y "percheros", sin exceptuar estado ni condición.

Todos los críticos y lectores hemos sido, como Sancho Panza, quijotizados, llegando a querer a este personaje como a las "telas" de nuestro "corazón" (II, XIII). Sin embargo, volvemos sobre nuestros pasos porque no somos tan valientes y temerarios como para que, siendo francos y sinceros, digamos verdades que a otros llevarían a la horca; o para que éstas sean celebradas como una gracia, una simple chanza intrascendente, como le ocurrió siempre al mismo Don Quijote, porque, dice Antonio Moreno a Sansón Carrasco, Dios habrá de perdonarle la tontería de querer volver cuerdo al primero, el loco más gracioso cuyos desvaríos son motivo de placer. ¿Aquéllas "locuras" fueron vaciedades que carcomen el seso y desnatan el entendimiento? (II, LXII), ¿meras sandeces dignas de lástima? (II, LXV), ¿fueron las simples imprudencias de un sabio?

Aunque contestemos que no, es obvio que no nos ha movido, empero, a enristrar una lanza y cabalgar por unos campos de Montiel o a los que estamos unidos afectivamente para desfacer entuertos, según frases de José María González de Mendoza, El Abate de Mendoza, sino que retrocedemos a sabiendas de que esta clase de inusuales actos se darían en la encrucijada que es blanco de ataques inmisericordes, de los cuales sacaríamos rota la cabeza, una oreja de menos, y las persecuciones y castigos de fuerzas represoras como la Santa Hermandad (I, X). Acobardados seguimos, como en el teatro, representando varios papeles de modo que con una lengua decimos la verdad y con la otra lo que nos conviene. A diferencia del hidalgo manchego siempre estamos manoseando nuestra autoestima.

$\mathrm{Al}$ enterarnos de su género de locura o falta de juicio (I, XIII), nos debatimos entre nuestras naturalezas bella y fea. La primera experimenta una gran simpatía y felicidad, si no por tenerlo como amo (II, XXIV), sí porque fue imaginado. Y admitámoslo, se da a querer tanto que entendemos la obsecación de Feliciano Ortega y Agurribeña de que las anotaciones al margen de un ejemplar de 1605, 
que él tuvo entre manos, eran de Cervantes, y que ni Marcelino Menéndez y Pelayo lo haya convencido de que la letra es del siglo XVIII.

El amor o locura de Eros en complicidad con las Musas. Militando bajo la, para él, amorosa bandera de la caballería, Don Quijote intentó hacer el bien a todos y el mal a ninguno (II, XXVI). Luz y espejo manchego, decorado con la inclinación de las "almas simples", que no manejan el fraude, el engaño y la malicia, sino la llaneza y la verdad, cayó bajo las flechas empapadas de sustancias delirantes de Eros: amó más que la lumbre de sus ojos a Aldonza Lorenzo, a quien no engendró ni parió, según le aclara a Sancho, aunque sí la rebautizó como Dulcinea del Toboso, nombre sonoro y musical de gran dama, a la que nunca traiciona con la princesa Micomicona, entre otras, porque la adora como una reliquia (I, XXX). Cervantes se regodea en las exageraciones del amor, delirio del erotismo en complicidad con las musas que Don Quijote profesa a quien un narrador omnisciente describe como la mejor saladora de puercos. Él la vio unas cuatro veces y la amó en silencio, con un honesto mirar, en frase de José Ingenieros, y con abnegación y lealtad inquebrantable durante doce años. Aldonza es la señora de sus pensamientos. Por lo mismo, no se deja engañar con la falsa identificación que hace Sancho de tres aldeanas en su jumento como ella y su escolta: sólo mira conmocionado la realidad, aunque sí acepta la excusa del embrujamiento de ella, perseverando en la interpretación de la ojeriza que los magos le tienen a él. Su buena fe ha de aceptar las excusas mentirosas de Sancho el bueno.

Bajo la luz de Erasmo, hacer de Aldonza Lorenzo una Dulcinea no es más que un desvarío del amor, que es tal cuando alguien considera a otro individuo como el más bello, o hermoso sin tacha, grave sin la soberbia de los linajes, gallardo, discreto, agradecido, honesto y cortés, y hasta, si es mujer, dice Erasmo, una Penélope rediviva, todo lo cual sólo quiere decir que quien cualifica está enamorado, que el objeto de sus afectos le infunde fuerza en las peleas y lo ayuda a ir viviendo. Lo demás son intelectualizaciones de un tipo de generosos y enaltecedores afectos interpersonales, que no éstos mismos. También el que ama a un animal compañero, como Rocinante, un maltrecho caballejo se transforma para él en un corcel tan magnífico como el Bucéfalo de Alejandro o el Babieca del Cid.

Contrariando las loas del platónico o casto amor quijotesco, tan ponderado por José Ingenieros, Unamuno dice que, en un hombre que en aquellos días frisaba la vejez, estos sentimientos por una joven llevaron una fuerte carga de sensualidad; que la continencia no borró el deseo carnal: "ardías en deseo de Aldonza Lorenzo, como no te atreviste nunca a requerirla de amores. No pudiste romper la vergüenza que te sellaba, con sello de bronce, los labios." (p.226)

El loco amor caritativo. La fealdad contra la belleza o por qué un loco hizo cientos. El Abate de Mendoza escribe que: 
Afirma certeramente un refrán que un loco hace ciento; y es de tal manera activo el contagio que aun siendo el loco 'sombra de sombra y sospecha de una posibilidad' como el muy sensato 'Amigo Manso' de Galdós, puede inficionar con sus locuras a quien las lea relatadas. Pegajosísimas son las de Don Quijote. (p.332)

Y lo son porque, sigue González de Mendoza, Cervantes hizo algo mejor que imaginar un mundo encantado aparte del real, encantó a la vida, de modo que su obra deviene un juego de espejos en donde nos miramos: "no es él [Don Quijote] quien ve su heroicidad en sus entrañas - asegura Unamuno-, sino nosotros, sus compañeros de ruta. Sus encuentros sí sólo vieron sus extrañas." (p.189) Penetremos un poco en esas entrañas. Alonso no sólo amó a Aldonza, sino que, sin limitarse como los curas a pedir paz y sosiego al cielo, se hace activo ejecutor de la justicia (I, XIII), hija de un amor que da presencia a este valor, encaminándose con la fuerza de su voluntad (I, XXI) a satisfacer agravios (I,VII, XIX); a desfacer entuertos y sin razones; a satisfacer deudas; a socorrer o dar remedio a miserables, flacos, menesterosos y afligidos (I, XIII y XXI); a defender, como Cardenio, doncellas, y a devolver la honra a las mujeres contra locos y cuerdos (I, XXV y XXIX). El Quijote abogará por un mozo azotado y liberará a los galeotes que iban forzados por el rey, haciendo valer la justicia distributiva y conmutativa. Debido a su "suprema bondad", en calificativo de Maeztu (p.28), sigue el designio de su buena fe y mejor talante. Es, en opinión de Maeztu, "el prototipo del amor, en su expresión más elevada de amor cósmico [...]. Todo gran enamorado se propondrá siempre realizar el bien en la Tierra." (p.72)

Don Quijote se considera obligado a amparar a los desgraciados oprimidos sin distinguir si sufren por sus culpas o por sus gracias (I, XXXI). Por su espíritu justicialista no duda en llamar a las fuerzas represivas de la Santa Hermandad gente soez y mal nacida (I, XXXVIII). Como alma bella no sólo escucha al otro, reconociendo sus limitaciones, sino que comparte la comida en un mismo plato, y bebe en un mismo recipiente con sus criados (I, XI) y con los pobres a quien honra, como los ricos tienen quien los lisonjee porque, al fin desnudo nació y desnudo se halla, de modo que ni pierde ni gana (II, VI). E incluso reconoce la compasión y loables intenciones del lladre Roque Guinart. Si esto es así, no entiendo en qué pudo basarse Alfonso Saldías que, según Eduardo Benot, en apreciaciones de González de Mendoza, aseguró que esta figura representa la aristocracia conservadora y Sancho la democracia pura. En contrario, tampoco deja de admirarme que hagan de Cervantes un fundador del libre pensamiento o hasta que lo examinen bajo "la bermeja luz del Materialismo histórico" (p.352), según las indagaciones del mismo Abate de Mendoza. 
Estoy de acuerdo con Manuel Azaña que la novela habla de una epopeya profundamente cristiana. Unamuno sentencia "Hay algo más íntimo que eso que llamamos moral [...]; hay algo más hondo que el Decálogo [...]: hay un espíritu de amor" (p.222), de amor caritativo que emana de la bondad o, dicho con las palabras de este mismo filósofo, del ser cuyo centro está en él mismo, pero que en su obrar se polariza o descentra (p.180).

Un "bien intencionado" no escarmienta ni sospecha malicia aun estando enjaulado (I, XXIII y XLVIII). Las desgracias, el sufrimiento, no aminoran la compasión de esta caritativa "alma de cántaro" que no tiene nada de bellaca ni artificiosa (II, XII), sino mucho de simple, aunque con bastante "sal en la mollera", porque desde las primeras hasta las últimas páginas del relato nos enteramos que no es mentecato, sino muy entendido en teología, en matemáticas y en astrología (II, XVII) y razonador muy discreto, alejado de la sandez del que no siente nada, y tan creativo o poeta que todo lo alcanza y sabe (I, XVIII y II, XVII). Y es tan inteligente que decide una forma de vida o "fineza de su negocio", a saber, volverse loco y desatinar en toda ocasión, a sabiendas de que irá por lana y volverá trasquilado (I, VII), de que vivirá muchas malas aventuras en el transcurso de su existencia (I, XIII) porque la mayoría de sus empresas le saldrán torcidas (I, L) y, porque, en definitiva, su destino es que lo coma una especie parecida a la zorra, lo piquen las avispas y hollen los puercos (II, LXVIII). Él sabe que hacer el bien a villanos es echar agua en el mar (I, XXIII), porque son desagradecidos; que la virtud del valeroso es envidiada (I, XLVII), y, para colmo, es más perseguida por los malos que querida por los buenos (I, XLVII); y, en suma, que las desdichas son anexas a su profesión de fe. Sin embargo, a este tipo de optimista las desgracias que sufre no ahuyentan su compasión, ni las burlas, ni los golpes, ni las jaulas lo hacen desfallecer: cree que finalmente el bien saldrá vencedor e iluminará la Tierra (I, XLVII) de manera que es, pues, como sintetiza Tomé Cecial, un vehemente loco por su propia voluntad, que hace "tonterías" a sabiendas de que no dejará de hacerlas (I, XXV), y que no tiene juicio excepto cuando se le antoja al cielo dárselo por breve tiempo (I,XXIX), es decir, que es un loco bizarro con lúcidos intervalos (II,XVIII).

En esta fase histórica del Hierro (I,XIX), en que, a querer del cielo, nació Don Quijote, el "calvatrueno" que adornó La Mancha (I, LII) se ha perdido de vista el principio del amor caritativo que brota espontáneamente del Uno, en términos de Plotino, del Dios que, por sus raptos de sabia locura, reparte bienes sin pedir a cambio pan y cordero ni demás ceremonias, y que nunca monta en cólera porque no se le rinda culto público, en frases de Erasmo. Don Quijote ama a Cristo sin que lo mueva la esperanza de la gloria ni el temor ni la pena, sino por servirlo, sin más (I, XXXI). Y esta su deidad es, por definición, un ser 
bueno y, por lo mismo, bello (de bellum, que viene de bonum por vía del diminutivo bonellum abreviado en bellum). Esta hermosura, en palabras sabias de Marcela, no depende de unos rasgos físicos, sino que enamora, es amable o digna de ser amada, porque rinde la voluntad con su gracia (I, XIV). El Caballero de la Triste Figura es un escrupuloso defensor de la fe católica en la línea reformista. Como lector de Erasmo, Cervantes estuvo consciente de que la Razón y la Verdad que el clero predicaba eran simples tretas manipuladoras, como nos explica Wilhem Dilthey; pero la religión fue su guía. Cuando Sansón Carrasco lo excomulga por haber puesto la mano violentamente en cosa sagrada, es decir, en unos sacerdotes, alega que las puso en un lanzón, sin pensar que ofendía a la Iglesia que adora. Incluso está tan imbuido del dogma social de los tiempos de la caballería, de los (hipotéticos) ideales de los Cruzados, que sus sentidos se ilusionan con las manadas de ovejas y carneros como ejércitos de católicos y musulmanes enfrentados (I, XVIII). Tales desvaríos se deben a que el cristianismo es, para él, un ideal de bondad, alejado del espíritu de venganza (II, XI), que lo impele a pagar con ventaja del ofendido las cuentas de los males que le haya cometido sin percatarse.

Luego, para el bueno e inocente de Don Quijote, habiendo durado mucho el mal, o la sociedad dura como el hierro, estando al servicio de Dios, el bien se encuentra cerca (I, XVIII), porque existe y debe incrementarse. Sin embargo, Miguel Cortacero y Velasco -Cervantes y el Evangelio, o el simbolismo del Quijote (1915) - se coloca fuera toda medida cuando encuentra en Don Quijote una reproducción del simbolismo bíblico. Para colmo, anota El Abate de Mendoza, Baldomero Villegas en La Revolución Española. Estudio en que se descubre cuál y cómo fue el verdadero ingenio de Don Quijote... (1903) "descubre" que la fruta en la mesa del gobernador Sancho Panza alude "a la del Jardín del Paraíso, fruta de la ciencia del bien y del mal" (p.358). En contrario, magnificar la expresión de que "con la iglesia hemos topado, Sancho", y a partir de ella obstinarse en atribuir múltiples sútiras anticlericales a la novela, forzando sus significados y hasta posibles sentidos, es una simple loca proyección de, por ejemplo, Francisco María Turbino en Cervantes y el Quijote, sin olvidarnos de Benigno Pallol, o Polinous, que en Interpretación del Quijote, en un extremo de insensatez, que "fundamenta" en enrevesados anagramas con letras de más o de menos, considera el texto como una inventiva contra los libros sagrados y sus derivaciones, anota González de Mendoza, de manera que para Benigno Pallol Dulcinea simboliza España; Maritornes, la iglesia; Don Quijote y Sancho, el pueblo en lucha contra el absolutismo de los monarcas y la "opresión dogmática sobre la conciencia. ¡Nada menos!" (p.352).

Antes al contrario, vuelvo a decir, nuestro caballero andante fue un conspicuo defensor del cristianismo y de sus metas e instituciones. En busca de hilos conductores analicemos, por ejemplo, el Libre de l'orde de caballeria escrito por 
Ramón Llull. En I, 2 éste afirma que se ha corrompido el amor, la caridad, la justicia, la veracidad y la lealtad de la Edad de Oro, el metal que no se corroe, sobreviniendo el menosprecio, la mentira, el ímpetu a la guerra y la enemistad. Alonso Quijano cree en esta degradación histórica y, limpiando de orín y moho las armas de sus bisabuelos, trata de restaurar el paraíso perdido para servicio de su república y su honra y fama personales. En estas detestables circunstancias nuevas, en que la pólvora y el estaño dominaban el valor del brazo y la espada (I, XXXVIII), aparecieron en escena los caballeros, que, escribe Llull, imponen por temor la verdad y la justicia (II, 9). La nobleza de propósitos de estos defensores de la fortaleza de la fe, la esperanza y la caridad, que necesariamente van acompañados de un escudero, sigue este filósofo, no tiene relación de continuidad con la altivez de los altos linajes, porque no basta la nobleza de ascendencia, sino que es necesaria la del coraje $(\mathrm{I}, 16)$ para destruir a los malos, traidores, ladrones, hurtadores (II, 23 y III, 4), y defender reinos y mantener viudas, huérfanos y necesitados (II, 19).

Para Don Quijote el linaje que se hereda, el de alquimia, ha acabado de punta, como una pirámide invertida (I, XXI), frente a la nobleza de acciones, esto es, el oro o la salud de los reinos. Los nobles linajudos reconocen el mundo en un mapa; los caballeros andantes, como él, con los pies (II, IV). Mientras el hidalgo Diego de Miranda recula llamando locura a la temeridad (II, XVII), el Caballero de los Leones tiene una fortaleza temeraria. En fin, no le falta razón a Maeztu: muchas criaturas de las artes nos meten de lleno en los problemas éticos porque son buenos o malos, y sólo los nulos son indiferentes, porque hasta los amorales pícaros nos hacen replantearnos nuestra escala de valores.

La contagiosa locura según los filólogos. Pese a las anteriores anotaciones, José María González de Mendoza dice que para Rodríguez Marín una "nutrida caterva de intérpretes" "enquijotados" "cayeron en la manía de ver como "tratado cabalístico de recóndita filosofía' el que es 'mero libro de entretenimiento' [...], y dieron de su significado interpretaciones delirantes" (p.332) que presentan a Cervantes como viajero, geógrafo, marino, economista, fisiólogo, psiquiatra, inventor, músico, pedagogo, jurisperito, administrador militar y teólogo. Por su lado, Auerbach también recuerda que la crítica filológica intenta demostrar que este autor no quiso provocar la admiración por un idealismo incondicional, sino ofrecer un pasatiempo con los extravíos de un orate, en su acepción etimológica, derivada de aura malsana, de tener la cabeza llena de viento o de ligerezas, de prejuicios infundados o ilusiones que se forjan en el magín.

Indiscutiblemente que se han acopiado a lo largo de más de cien años centenares de documentos importantísimos y que se han hecho aportaciones básicas (que deshacen errores tan burdos como que Rocinante no es yegua, confusión 
debida a que la palabra francesa para rocín es femenina). Muchas interpretaciones impertinentes fueron deshechas por Pérez Pastor, Rodríguez Jurado, Benot, García Rey, John Bowle, Clemencín, Valera, Menéndez y Pelayo, Américo Castro, Salvador de Madariaga, y, especialmente, por Francisco Rodríguez Marín en Nueva edición crítica con el comento refundido y mejorado (1947-1949), así como en México por Francisco Icaza -Supercherías y errores cervantinos-, el mismo Abate y Ludovic Osterc, entre otros. Esta formidable labor contextualizadora, no obstante, no puede ni debe frenar la locura de musas o delirio interpretativo de la hermenéutica, siempre que éste no viole los márgenes que acepta el texto, visto más allá de las estrictas anotaciones filológicas. En otras palabras, tan grande fue la "alta cumbre" de su locura y el "profundo abismo", no por ello menos glorioso, de su simplicidad "monomaniática" (II, I), que Don Quijote ha arrobado a los innumerables críticos o comentaristas de sus hazañas, haciéndolos encontrar nuevos mensajes en el texto, que rebasan las estrictas y conscientes intenciones creadoras de Cervantes, y otros sentidos que dependen de un horizonte cultural que se pone y sobrepone y adecua a la obra mediante un diálogo, basado en preguntas, que ni él ni nadie pudieron sospechar, y que la reactualizan, insuflándole nueva vida. Comencemos por las alucinaciones quijotescas y una de sus interpretaciones.

La extravagancia y las similitudes. De entrada hagamos una síntesis. En la primera y segunda parte del Quijote, un individuo seco de carnes, enjuto el rostro, y de oscuro apellido - Quijada, Quesada, Quejana-, tomemos el de Quijano, que sin pretender ser Neptuno - aunque si Júpiter no lloviera él lo haría cuando se le antojare-, ni que lo tengan por discreto, decide ser hasta la muerte, como Amadís, Palmerín y Tirant lo Blanc, un caballero andante $\left(2^{\mathrm{a}}, \mathrm{I}\right)$ que disfruta cada momento de su existencia defendiendo reinos, amparando doncellas, y socorriendo a huérfanos, humildes y pupilos, contra soberbios, para dar a entender al mundo el error de no renovar la feliz edad dorada que, para él, (I, X) fue el espacio donde se ignoraron los conceptos de "tuyo" y "mío"; donde la gente vivió en aquella púdica desnudez en que nacemos (I, XXV), y practicó el amor que todo lo iguala (I, X); donde abundaron los bienes naturales y las aguas transparentes, que no los lujos, que colman las necesidades; donde, como en la ciudad de Dios descrita por San Agustín, reinaron el ímpetu pacifista, la amistad y la concordia en las almas simples, sin recovecos ni maldad. La "fineza del negocio" de Don Quijote fue, pues, que, bajo la bandera del amor, desatinó en toda ocasión porque "loco soy y he de ser", se declara, aunque muy distinto a los cuerdos locos que quitan la honra a las mujeres $\left(1^{\mathrm{a}}, \mathrm{XXV}\right)$.

No hay duda de que el hidalgo manchego además de idealista, por la lectura de las novelas de caballerías tuvo, en palabras de Carlos Fuentes, el juicio desvelado y perdido en un pasado remoto, que proyectó hacia un mañana muy lejano, 
dejando de lado las preocupaciones por el sobrevivir cotidiano. Sus legendarias aventuras retoman el tema erasmita de las apariencias ilusorias, en terrenos de las cuales aquél luchó con la espada desenvainada.

Don Quijote fue algo más que un extravagante. ¿Por qué? Michel Foucault piensa que con la novela que trata de sus locuras se canceló un universo de interpretación mágica que iguala los signos y las cosas. "Don Quijote no es el hombre extravagante, sino más bien el peregrino meticuloso que se detiene en todas las marcas de la similitud. El héroe de lo Mismo" porque incluso él es un "Largo grafismo flaco como una letra, [que] acaba de escapar directamente del bostezo de los libros." (p.53) Sus aventuras son una escritura errante: él ha sacado de las novelas de caballería qué debe ver y hacer.

En un enrevesado juego de espejos entre autores -el historiador arábigo Cide Hamete Benengeli más el que parte del cartapacio de éste y Avellaneda-, y de traductores, desde el morisco que puso en castellano las páginas de Cide, más otros, que a veces se ponen en duda entre sí, nos enteramos que un hidalgo rural, de tanto leer libros, dio en la locura limitada a la sola idea de resucitar la caballería (aunque no sólo leyó las novelas al respecto, sino también las pastoriles y muchos otros textos de varios temas, que los críticos suelen dejarse en el tintero). Por esta decisión, Alonso, después de un rito iniciático en manos de un ventero que, según la voz explicativa, fue una ceremonia para reventar de risa, o sea, un renacimiento que, como el bautismo, lo renombra, se convierte en Don Quijote de la Mancha, quien desde entonces ajustó con más ganas la realidad a la óptica de Roldán o Don Belanís de Grecia (I, II), los optimistas héroes que destierran la melancolía (I, XLIX), aunque hayan llenado el mundo de encantamientos, desafíos, luchas irrealizables, de fantasmas - endriagos, gigantes, serpientes que hacen las veces de escaleras, gnomos y magos encantadores como Frestón- y pociones que todo lo curan. Las hazañas quijotescas, tan irreales como las de los personajes antes mencionados, aunque el texto cervantino irónicamente dice que son locuras nunca vistas, se analogan con la letra mediante desatinados reflejos por semejanza: las sombras en la pared o los molinos son gigantes que Alonso acuchilla o embiste; su sudor es sangre; las ventas se tornan castillos con torres y capiteles de plata; la bacía del barbero, en el yelmo de Mambrino; el porquero que llama a su piara con un cuerno, un enano que anuncia su llegada; unos monjes con sobrepellices oscuros y sombrillas, raptores de una princesa; las manadas de ovejas y carneros, ejércitos de moros y cristianos; los odres de vino tinto rotos, cabezas que caen o cerebros que se derraman... Cualquier indicio de diferencia es para él, dice Foucault, una metamorfosis o un engaño de los sentidos debido a encantamientos. Más tarde el texto se repliega sobre sí mismo o se "hunde en su espesor" (p.55) porque Don Quijote mismo, 
convertido en "signo errante", enajenado en las analogías, debe ser fiel al libro que se ha escrito sobre sus correrías, protegiéndose de falsificaciones y continuaciones apócrifas.

La relativa extravagancia cultural del protagonista en cuestión se debe, pues; a que asume un principio de realidad anacrónico, a que oye un discurso en el cual las palabras "centelleaban" en semejanza universal, en un "homosemantismo" que no deja de proliferar. Sus contemporáneos, en oposición, saben que corren escritas quiméricas fazañas que carecen de referencia, esto es, que la correspondencia entre esos signos o lenguajes, y sus marañas de relaciones, y las cosas es fantasiosa.

En apreciaciones de Foucault desde aquel ahora tales diferenciaciones ya habían tomado su lugar; desde ese momento, los lazos mágicos entre signos y cosas sólo se salvan cuando se toma el texto como literatura, como hijo de un poeta que, usando la alegoría y demás figuras retóricas, encuentra parentescos dentro de lo distinto. Hasta el siglo XVIII, continúa, se caracterizaba a un loco como aquel que ignora a sus amigos y reconoce a los extraños, invierte valores y proporciones: es el diferente en la medida en que no reconoce la diferencia.

Sin embargo de los indiscutibles aciertos de estas observaciones sobre la magia y las ilusiones de los sentidos, causados por la cultura, la obra cervantina es más compleja. En primer lugar, el sentido común de la época en que transcurre la acción no está más avanzado que el de Don Quijote, sino que aún muchos estaban convencidos de la veracidad de la letra escrita, de las excelsas glorias de los Cruzados, y tan poco distinguían signos y cosas que mandaban al fuego los libros como algo en sí dañino, bajo el presupuesto de que cada caballero andante tuvo un sabio que escudriñó el fondo de sus pensamientos y hasta sus niñerías (I, VIII), o, peor, aquella gente purificaba con hisopos, conjuros y agua bendita los textos para deshacer el poder de los encantadores $(I, V)$. Aún más, Foucault se equivoca al suponer una evolución unidireccional en que cada etapa supera a las anteriores. Si el canónigo asegura que las fantasías han envenenado al vulgo y turbado a los ingenios, él mismo manifiesta que existe el libro veraz por excelencia, la Biblia, en donde se aprende historia literal o la estricta verdad de los hechos acontecidos. Pero... las preguntas se suceden en tropel sobre lo descrito literalmente en las Sagradas Escrituras y en las vidas de santos y demás paladines de la fe - ¿existieron o no un Santiago Matamoros y un San Jorge defensor de doncellas? Don Quijote responde que las separaciones entre historia, crónica y novela no son tajantes, porque todas van rescribiéndose no al margen de innumerables fantasías, y en prueba dice que corren libros impresos con licencias de la censura, que han sido celebrados por gente de cualquier estado y condición, que hablan de Héctor y Aquiles, de Bernardo del Carpio, del Cid, así como de los fabulosos hechos que ocurrieron en ciertos 
reinados españoles, y otros que dan fe de las extrañísimas batallas por el Santo Grial y de las sobrenaturales vivencias de los caballeros de Santiago y Calatrava.

Y todo lo anterior nos lleva a que los contemporáneos de Alonso Quijano, él y nosotros, no distinguimos siempre los signos de las cosas, y que, por ejemplo, consideramos tabúes ciertas palabras, o bien seguimos hablando del alma, de Dios y de los santos que nos protegen del mal de ojo. También decir que la literatura no da conocimientos de la realidad que describe, que es un universo cien por ciento autónomo, es una pobre noción de ella: su intrincado universo de simbolizaciones y de referencias puede resumirse en aquella fórmula ritual de los cuentos maravillosos de que lo dicho "era", y "no era" si se quiere interpretar bajo el principio de una estricta correspondencia. Carlos Fuentes anota con buen tino que si bien Don Quijote impuso sus lecturas a las situaciones que experimentó, ni lo que experimentó ni lo que hizo sólo fueron "espectros de papel” (p.82), porque a golpes de su fantasía rasgó los velos que ocultaban la verdadera y pobre orientación de los hechos que caracterizaron aquella fase del hierro. Además, en la novela el universo entero es visto como una serie de lenguajes escénicos que hacen de la realidad un teatro, que no deja de ser una realidad: Dorotea, Sansón Carrasco, Ginés de Pasamonte y los duques que dieron a Sancho el gobierno de la ínsula - por cuya actuación por primera vez Don Quijote creyó en sus ideas fantasiosas, mientras que el resto del tiempo admite que sus experiencias van fuera de los términos de las que tuvieron los demás caballeros andantes (II, XXXII) - llevan a cabo una serie de metamorfosis, de trucos que encantan como los de los prestidigitadores, y que van más allá de lo que sería menester para sus propósitos, observa Auerbach (p.331).

Por último, los diversos conocimientos manejan divergentes principios de realidad, que, además, cambian históricamente, aunque no ha existido uno al margen de una loca dosis de magia: ninguno llega a esencias, sino que siempre se está en camino hacia la verdad, siempre en fuga: "En realidad no hay diferencia - escribe Erasmo- entre los que sumidos en las sombras de su ignorancia, la caverna de que hablaba Platón, se dejan engañar por las apariencias de las cosas, sin desearlas y sin satisfacerse con ellas, y el sabio que las ve tal como son en la realidad" (p. 80).

Los locos arcanos de la literatura: las extravagancias de los signos. En cada campo de estudio y en cada situación manejamos distintos principios de realidad, que nos permiten aceptar, por ejemplo, un número indeterminado de seres en la pintura y la literatura, mientras los naturales son en número finitos, dice Leonardo de Vinci. El problema es que los confundamos, como le sucede a nuestro protagonista, cuando podríamos no hacerlo. Pero no siempre podemos. Somos bastante "mentecatos". La tesis de las similitudes entre palabras y cosas implica que éstas se correspondan entre sí. Bajo este presupuesto, y dado el 
hecho de que en La Galatea Cervantes puso a sus amigos bajo pseudónimo, muchos investigadores, algunos contemporáneos de él, como Manuel de Faria y Sousa, según informa Eduardo Benot en su prólogo a Cervantes y su época de Ramón León Máinez, se han ocupado en encontrar los modelos vivos, las refencias precisas, de los “607 hombres y 62 mujeres que bullen en la incomparable novela" que supuestamente pasaron de la realidad a la ficción, dice José María González de Mendoza, como si fueran los estrictos modelos que sirvieron para bosquejar los personajes, y de pasada El Abate escribe que hay muchos problemas de más urgente solución; pero que esta analogía mágica carcome a un número indefinido de investigadores que consumen su existencia en querer esclarecerlas, como si la novela fuera un libro de Historia (p.334). Así, en Juicio analítico del Quijote (1863), Ramón de Antequera quiso identificarlos con vecinos de Argamasilla de Alba: Dulcinea resultó ser Ana María Zarco de Morales, hidalga del Toboso, y Don Quijote, Rodrigo Pacheco de Quijana, un noble resentido por los amores de nuestro escritor con su hermana, que lo mandó encarcelar en esta población manchega, aunque en aquellos tiempos no existió ahí la supuesta cárcel. De este sujeto con ojos hundidos y barba rubia acabada en punta, o sea de este "Don Rodrigo que da qué hablar”, en título de El Abate, existe un retrato. Pese al mentís de Astrana Marín, Manuel Cervantes Peredo y de Andrés Ovejero, celebran el hallazgo Cayetano Alberto de la Barquera y Lereido y el chileno Augusto D’Halmar, mientras Azorín testimonia esta tradición argamasillesca.

En la "Vida de Cervantes", Jerónimo Morán reproduce un artículo de Navarrete donde se analizan los nombres de los capitanes de los ejércitos ovejunos. Para Nicolás Díaz Benjumea - La estafeta de Uganda, o Aviso... y El correo de Alquife, o segundo Aviso... - la figura del encantador que le tiene ojeriza a Don Quijote es una queja de Cervantes contra Juan Blanco de Paz que hizo fracasar una de sus tentativas de evasión de Argel, y mediante unos malabaristas juegos lingüísticos afirma que el apellido del real Sansón Carrasco fue Blanco y el del clérigo perniquebrado del episodio del cuerpo muerto, López de Alcobedas.

Dentro de tan ociosas chifladuras, Atanasio Rivero -Memorias maravillosas de Cervantes - descompuso en anagramas partes de la novela concluyendo que el falso Avellaneda fueron Gabriel Leonardo de Albión y el dramaturgo Antonio de Mira de Mescua. Los dos últimos hallazgos fueron pompas de jabón o engañifas que deshizo Rodríguez Marín con "unos cuantos papirotazos”, dice El Abate de Mendoza (p.332); pero he ahí que este contagioso alocamiento hizo que Rodríguez Marín estuviera convencido de que la figura del hidalgo manchego fue delineada a partir de Martín Quijano, contador de Galeras Reales, o quizás de Alonso Quijada, pariente de la esposa de Cervantes. 
Otra manía de John Bowle y Víctor Hugo, cuyos fines sólo pueden ser las conmemoraciones, quiere que los dos titanes de las Letras, Shakespeare y Cervantes, coincidan en la fecha de su muerte. Y Esteban Burnet -Don Quijote, Cervantes y el siglo $X V I$ - no duda en el paralelismo entre las biografías de nuestro autor y Dostoievsky.

¿Quién es el loco? Para Erasmo cien bocas con sus respectivas lenguas y una voz de bronce serían insuficientes para dar a conocer la infinita variedad de locos y de "locuras", éste no es, por ende, un concepto preciso, aunque el poder de dominio lo diagnostique tan usual y dolosamente. Para Carlos Fuentes su significado está tan lejos de lo absoluto que Pascal acertó en su dicho de que los hombres son tan necesariamente locos, que sería una locura, en razón de otro giro de ella misma, no estar locos. (p.68) Hoy, los especialistas, con Freud a la cabeza, lo evitan, sustituyéndolo con una extensa terminología técnica, en el entendido de que la mayoría de "trastornos mentales" forman parte de las generalizadas reacciones y conductas habituales: sólo unas indefinidas cantidad, duración, cualidad y relaciones de "extrañezas" son sintomáticas o justifican que se hable de alguna patología.

Qué decir, entonces, de un cuerdo que lo está por ser loco o, mucho mejor, de un loco que tira a cuerdo según lo define Diego de Miranda en la novela. Esto es, qué decir de un loco que por su mismo estado es un cuerdo que ha perdido la razón, o que pisa en terreno falso, dice Erich Auerbach, dentro de un mundo bajo el perfecto orden del hierro en el que, exceptuándolo a él, y a otros desadaptados, incluyendo a su quijotizado escudero, todo está en su sitio; cómo entender a un loco que también es cuerdo y prudente, y esto último porque, alejándose de la literatura que reduce a nuestro hidalgo a un necio y descabellado personaje cómico que despierta una alegría parecida a la que obtenemos después de bebernos unas cuantas copas (pp. 37 y 331), nos enfrentamos a una personalidad extremadamente polimorfa. Cómo entender, en palabras del mismo Alonso Quijano, la razón de la sin razón que a nuestra razón se hace de manera que ella enflaquece (I, pról.). Cómo encontrar sentidos en este asunto con el obvio peligro de que perdamos el juicio o se nos seque el cerebro. En este asunto ha resultado profética la multicitada observación de Ortega y Gasset de que "Lejos en la abierta llanada manchega la larga figura de Don Quijote se encorva como un signo de interrogación." (p.75)

Muchos lo liberan de la locura o la aminoran. Auerbach distingue la enfermedad mental de los curables desvaríos de Alonso. El noble sentimiento o grandeza idealista quijotesca lo inspira Cervantes a sus lectores, dice, aunque descanse sobre una ilusión vana (p.321) y se presente de modo grotesco e insensato (p.322). Su honestidad, dice a la letra, aun sin proponerse un efecto concreto, da en el meollo de los conflictos latentes debido a su dignidad. Desde el Renaci- 
miento esta virtud, que adorna a Don Quijote, se consigue, según la filosofía en boga, mediante sesudos cálculos de la razón, que no del sentimiento, que eligen entre tareas moral e intelectualmente positivas, rebasando los estrechos límites de las ambiciones personales: Pico della Mirandola. Coincidiendo con esta idea, Auerbach divide a nuestro personaje: su bondadosa sabiduría, su encono y su dignidad, propias de un sujeto juicioso y equilibrado, ponderado, razonable, amable y mesurado (p.328), son independientes de su locura o desvarío monomaniático (p.325), que el crítico iguala con lo demoniaco y paradójico (p.329):

Su sabiduría y su bondad son independientes de su locura y se manifiestan a pesar de ella. Es verdad que una locura como la suya sólo podría darse en un hombre noble y puro, y lo es también que la sabiduría, la bondad y el decoro iluminan su locura.y la hacen aparecer amablemente.(p.327)

Y ¿quién dijo que la locura, entendida como desadaptación, siempre es mala y demoniaca e indigna? Sólo puede serlo desde la perspectiva de los adaptados a las perversiones de la edad de hierro; en contrario, esta locura positiva, o reserva de salud mental fuera de la norma, que pone al descubierto los aspectos sociales enfermizos, es decir, las desviaciones del camino a una utópica edad dorada, no tiene nada de grotesca, ni de ridícula ni de demoniaca e indigna.

Tampoco me parecen pertinentes las indagaciones de Auerbach acerca de los motivos por los cuales la personalidad del Quijote, cuyo sentido moral siempre es superior al de sus contrarios, no se perfila como una figura trágica; a saber, porque sus intenciones están mezcladas con la insensatez, de modo que sus actos acaban en resultados nefastos que él soporta estoicamente (p.328): la lucha trágica de un amante del prójimo presupone la intervención de la calculadora razón ante una realidad que discurre impertérrita (ibid). Ya lo había dicho Leonardo de Vinci en su Tratado de la pintura $\S 87$ que el amor para ser tal nace del gran conocimiento de la persona amada; si no, poco o nada se la ama. No obstante, a pesar de sus desvaríos o alucinaciones, Don Quijote sí conoce de qué pie cojea la edad de hierro, y con esto quiero decir que el texto es una novela humorística, esto es, una presentación que nos mantiene como las máscaras teatrales con una cara que sonríe mientras que la otra llora. La primera ríe cautivada con los equívocos, o frondosidad (término al que remite el de "locura") que distrae y deleita el ánimo, aparejada con la impactante gallardía y resolución, así como con la amenidad (de amoenus, hermoso, agradable, divertido) de quien acomete empresas por fabulosas que parezcan. La segunda llora por la incomprensión de tantos contemporáneos y coterráneos de un sujeto tan grande y lozano. Lo humorístico no es lo cómico. En ningún momento me parece cómica la hipotética incoheren- 
cia, que Ramiro de Maeztu cree detectar, entre la vejez cronológica de Don Quijote y sus sueños y anhelos de joven (p.54). La locura, dijo Erasmo, proviene de la ninfa de la juventud, del espíritu que no envejece.

El humor porta embozada una profunda y amarga crítica social que esconde la tragedia, aunque no la evade. Detengámonos en esto. Otra locura de este idealista, o utopismo anticipado desde los inicios de la narración, es que si sana de la "enfermedad caballeresca", querrá renovar la pastoral Arcadia, transformarse en el pastor Quijotiz (II, LIX). Empero, libre el juicio de las "sombras caliginosas de la ignorancia", el protagonista reconoce sus embelecos y disparates para regresar a su personalidad de Alonso Quijano. Ese tránsito a una cordura "normal y corriente", dice Auerbach (p.329), que se separa de la locura de Don Quijote, o recuperación de la "salud mental", es, no obstante, una señal inequívoca de que se muere, de que sin ideales, que siempre se hallan fuera del pragmatismo instrumental y allende de las elecciones entre los nefastos hechos reales, y cuyos ejecutores nunca sopesan las consecuencias de sus acciones nobles, una bella persona no tiene razones de peso para seguir vivo. Sancho Panza conmovedoramente le implora que no se deje morir, que le eche la culpa de mirarse vencido (II, LXXIV). Sin embargo, el epitafio de aquel hombre de bien dice "morir cuerdo y vivir loco" (II, LXXIV), que para mí significa que cuando se hizo sensato en la triste realidad del hierro, la melancolía o depresión lo acabó para siempre. "Y es que entre nosotros - opina Machado- lo endeble es el juicio, tal vez porque lo sano y viril es, como vio Cervantes, la locura." (p.418)

Maeztu externó un abierto reclamo de cordura: "El amor sin la fuerza no puede mover nada, y para medir bien la propia fuerza nos hará falta ver las cosas' como son. La veracidad es un deber inexcusable. Tomar los molinos por gigantes no es meramente una alucinación, sino un pecado." (p.72) En tono no belicoso, Agustín Basave se lamenta: "quisiéramos que el caballero manchego no caminase con ojos vendados a la realidad. Su ceguera nos duele. Con un caballejo, una débil armadura y un cuerpo no menos frágil no puede implantar [...] el ideal que se ha apoderado de sus pensamientos" (p.174). Si Basave recapacitara sobre su sugerente distinción entre la institución que fue la caballería, de ésta como inclinación vital de un defensor de la justicia, cuyo arrojo, valentía y temeridad dan una orientación a su existencia y a la de todos, quizás convendría conmigo de que no caben tales reclamos y lamentaciones, porque si un militante de la utopía se quitara las vendas, sabría que él solo no hará la historia y que sus metas no se cumplirán tal y como las pensó: que el curso de aquélla es producto de fuerzas encontradas, de choques y concesiones.

El verdadero idealista siempre pisa terrenos de lo imaginario - siempre es un quijote-, comportándose con la mirada puesta en un futuro que él ha imagi- 
nado. Coincido con Unamuno en que "se puede intentar la santa cruzada de ir a rescatar el sepulcro del Caballero de la Locura del poder de los hidalgos de la Razón." (p.142) Por suerte hay idealistas que no dejan de admirarlo, "lo indiscutible es que Don Quijote el hechizado - escribe Fuentes - termina por hechizar al mundo. Mientras leyó, imitó al héroe épico. Al ser leído, el mundo [el sanamente desadaptado] le imita a él." (p.78)

Unamuno comulga con la locura quijotesca cuya raíz es la bondad y el impulso querencioso, mientras reprueba la que quiere hacer el bien a palos, "reformar a tajo y mandoble" (p.80), como si aquel caballero andante, que discurría sobre la grandeza de las carreras de las armas y las Letras, hubiera podido ser un moderno pacifista o un san Francisco de Asís en tiempos aún próximos a las Cruzadas.

Mauro Olmeda está seguro de que la locura quijotesca, en un personaje que discurre con tan buen entendimiento, es un ardid que hace circular por el mundo la mejor de las sátiras, o "conspiración burlesca" (p.257) que destila un razonamiento subversivo que atacó los problemas más candentes de un tiempo y lugar (p.256). Cervantes hizo de la simulación misma, dice, el más formidable manantial de humorismo, concluyendo, en contra de lo que leemos en la obra, que en el episodio de Sierra Morena, la emulación quijotesca de Amadís y Roldán está hecha en "términos tan donosamente intencionados que sería ingenuo no ver en tales pasajes una muy consciente refutación de su locura supuesta.” (p.257) “Cervantes no dijo seriamente jamás que el más excelso de los personajes de su creación fuese un loco", sino un "ingenioso hidalgo", como si aquél término siempre fuera sinónimo de tontería, demencia o estolidez, y añade que, y esto es un resbalón mayor que echa por la borda el proceso de transformación del escudero, que a Sancho "no se le ocurre ni una sola vez [...] pensar ni decir seriamente" que su amo sea un "enajenado" (p.244), siendo que el texto informa que el primero va aceptando algunas quimeras del segundo, mientras otras las atribuye a la loca imaginación de éste, como el caso de la Dulcinea encantada; por ejemplo, ya avanzada la trama, se especifica que "maguer que era tonto se le alcanzaba que todas o las más acciones de su amo eran disparatadas" (II, XXX).

Además a Olmeda lo convenció Rafael Salillas de lo que éste consigna en el título de su investigación El gran inspirador de Cervantes. El doctor Juan Huarte y su examen de los ingenios, aunque Cervantes nunca haya mencionado a este alienista. Metiéndose en la camisa de once varas de las destemplanzas, asegura que despiertan fantasías pasajeras, ilusiones temporales de los sentidos que cualquiera sufre, dependientes, como su nombre lo indica, del clima, y aplicando sus tesis nos invita a que no olvidemos que nuestro hidalgo salió en busca de aventuras durante el verano, cuando en la Mancha la canícula es agobiante. Olmeda 
desecha cualquier padecimiento mental de Alonso Quijano (él reduce la locura a la falta de inteligencia), tomando en cuenta los temperamentos y los tipos corporales, porque, al decir de Hipócrates, aquél tuvo la complexión magra y enjuta de los sabios. Salillas aceptó esta caracterización probándolo, entre otras razones, en que el puerco es el animal "más estulto por la mucha carne que tiene." (p.253) Termina Mauro Olmeda asegurando con Carlos Gutiérrez Noriega que El Quijote es una "verdadera historia clínica."

Cuánto ha dado de qué hablar el método de similia similibus que aplica el improvisado psiquiatra Sansón Carrasco a José Ingenieros, quien encierra a nuestro loco, no taciturno y reconcentrado, sino locuaz (p.24), en tres caracterizaciones: una monomanía caballeresca en "solfa con otra pastoril" (p.35), que lo empuja a ostentar sus disparates (p.26); una megalomanía que le da la certidumbre de que habrá de conquistar reinos; y una erotomanía (p.31), o un delirio de grandezas o alta consideración de sí por la cual cree que las mujeres deben ir tras él. Ingenieros piensa que es absurda la "cura" de Alonso, porque "los monomaníacos sistematizados pasan generalmente del delirio de grandezas al de las persecuciones" (p.35): después de los lances con el Caballero de la Blanca Luna debió sentirse perseguido y vencido por sus enemigos encantadores. Le perdona a Cervantes este resbalón porque ni era ni "tenía por qué ser alienista, sino un hombre de Letras de su tiempo."(p.35) Por último, cuando Alonso se derrumba en la melancolía, según José Ingenieros no pierde su "razón anormal” (p.38), sino sus capacidades (se vuelve un demente), incluida la de delirar.

¿Quién escribió el Quijote? Las discusiones al respecto son acaloradas. González de Mendoza comenta que se impugnó a Rodríguez Marín diciéndole que en la novela se encuentra más de lo que acertó a ver Cervantes en su creación (p.348), que media cierta discordancia entre las voces que explican y describen los acontecimientos y una figura que va esculpiéndose en su grandiosidad. En una nota al capítulo L, aquel filólogo contestó que “'Los autores, aun durmiendo, suelen saber más de lo que escribieron que sus comentadores y críticos, por muy despiertos que estén o se imaginen'." (ibid). Tomando este delicado asunto, Esteban Burnet plantea la duda de si Miguel de Cervantes fue consciente de la grandeza de su obra, o si solamente creyó que había compuesto un libro divertido para alegrar espíritus mohínos. Para El Abate de Mendoza “El dilema parece absurdo; pero lo absurdo es dudar de que Cervantes escribió con plena conciencia lo que escribió." (p.364) En antítesis, Miguel de Unamuno lo atribuye a una inspiración no consciente que rebasa, sentencia brutalmente, el talento endeble que mostró en el resto de sus obras (comparación de textos que podría aplicarse a la producción de cualquier escritor). Redondea diciendo que el recurso de atribuir El Quijote a Cide Hamete Benengeli no es un coquetería 
literaria, porque "esa historia se la dictó a Cervantes otro que llevaba dentro de sí.” (p.525) Por absurdo que suene, El Quijote es hijo de la inspiración de las musas, las que nos dictan grandes aciertos, de cuyo descubrimiento no podemos dar cuenta porque nos llegan como un éxtasis, un delirio o manía iluminadora (Platón, Fedro), aunque claro que esto no elimina del todo la parte consciente del sujeto emisor. Es decir, como cualquier gran obra de arte se debe a una misteriosa conjunción de facultades conscientes y no conscientes, de sentimientos, la pasión incluida, y de saberes adquiridos que ocupan el campo de la conciencia y de otros que se tienen en una reserva mnémica. Conjunción por la cual la creación rebasa el plan y las intenciones creativas. La solución de este dilema es, pues, la locura:

quien se llegare a las puertas de la poesía - sentencia Platón- sin estar tocado de locura de Musas, confinado en que la técnica le bastará para ser un poeta, es un fracasado [...], la poesía del perito palidece frente a la de quien está poseso de locura de Musas. (p.108)

Las travesuras de Pluto. La divertida estolidez. El protagonista de la obra en cuestión dijo que su historia tendría necesidad de comento para entenderla. González de Mendoza precisa que: "La entendieron a tuertas aquellos que gustan de buscarle cinco pies al gato -que no tres: éstos los encuentra cualquiera. Inficionólos la locura del hidalgo, y dieron por aciertos de la perspicacia lo que eran descarríos de la imaginación.” (p.350)

Se delira también por las travesuras de Pluto, dios de las riquezas, que las distribuye tan fuera de criterio y medida que se le representa ciego y cojo, dice Erasmo. Este dios minusválido nos vuelve estólidos, nos insufla desaciertos, pensamientos ligeros, inconstantes, una ventolera irreflexiva y disparatada o alucinante: delirios o improntas que están fuera de la lira o surco de la obra. En la Barcelona fantaseada por Cervantes se oyó un discurso profético: “Tú eres loco, y si lo fueras a solas y dentro de las puertas de tu locura, fuera menos mal, pero tienes la propiedad de volver locos y mentecatos a cuantos te tratan y comunican." (II, LXII) Los mentecatos se dividen en dos, los que, sin proponérselo, nos juegan bromas pesadas, aburridas y sandias que nos sacan de quicio, y los cómicos involuntarios que nos meten de lleno en el relajo.

Entre los primeros cuento, siguiendo a El Abate de Mendoza, a Jacinto María Delgado, que en el siglo XVIII atribuyó a Cide Hamete Benengeli su Historia del ingenioso..., en que prosiguen los sucesos ocurridos a su escudero... Después de la muerte del que llama Quixántropo, Sancho Panza es cultivado hasta que adquiere juicio recto, una prudencia que lo aleja de empresas descocadas y modales 
tan pulimentados que recibe el título de barón y es nombrado Consultor de Cámara. Y henos aquí que el poder de dominio se sale con la suya domando a un individuo rebelde hasta hacerlo cortesano.

Nicolás Díaz de Benjumea asentó eruditas "lucubraciones" deslumbradoras que, Carlos Pereyra, citado por El Abate de Mendoza, enjuició, en tono de perdona vidas, como sutilezas graciosas si se atribuyen a un perturbado (p.379). Sólo reproduzco las apreciaciones al respecto de Cayetano Alberto de la Barrera y Lereido, en palabras de El Abate: los combates quijotescos con la lanza simbolizan "el gran mito de la humanidad, la lucha de la sabiduría y la fuerza moral reunidas en uno, con la fuerza material y la ignorancia reunidas en muchos. El amor del andante caballero no es el de Aldonza, sino el de la sabiduría. Dulcinea es el alma de Quijote objetivada, el anagrama exacto de Dina Luce, la 'digna donna luz' de Guinecelli, la donna philosophia de Dante, 'Beatitud o Beatrix'.”(p.378)

En el ensayo "Los descubrimientos de Villegas", González de Mendoza le otorga la medalla de las tonterías a Baldomero Villegas, cuyo estudio (1897) asienta que dado el oscurantismo y la tiranía en que escribió, Cervantes forjó un plan, "que no tiene desperdicio" (p.357), para burlar la censura y entregarnos sus pensamientos liberales y reformistas. Villegas desvela los "para-lelos", así, con guión (¿para-pasmados?, se pregunta El Abate): Dulcinea simboliza el ideal quijotesco de perfección; Sancho, el egoísmo y la vulgaridad; el cura y el barbero, el "compadrazgo" de intereses; los gigantes, el colosal poderío que se ha forjado en los países; y los molinos de viento son el "símil de una sociedad intransigente y fanatizada que se mueve automáticamente y arrolla y mata lo que se le pone por medio." (p.357) Frase por frase don Baldomero Villegas encuentra símbolos: las ventas, el palenque donde se discuten las cuestiones sociales, una especie de ágora; la piara llamada al son de bocina, los vividores de la sociedad congregados por la trompeta de la fama; el molino, la prensa que tritura las ideas de la oposición; los arrieros, los especuladores y traficantes de ideas; el mozo azotado y su patrón, coeficientes de la arbitrariedad; y Amadís de Gaula, Francia, aunque nada importa la minucia de que Gaula no valga por Galia sino por Gales. Su sagacidad se agudiza: Quijote es la contracción de "Qué hijote”, cuyo Don se debe a la elevación de sus intenciones, y de la Mancha porque nace en una España decadente, o sea, manchada (p.358).

Anticipándose a envidias, Villegas afirmó “'Sé que no ha de faltar quien diga que esto que yo creo ver en Cervantes, por un fenómeno de espejismo sobre su libro, no existe más que en mi imaginación'." (p.358); pero quien tal diga no tiene el talento para crear tan excelso y explicativo sistema de sociología de la literatura, que él ha captado debido a que, al haber transitado por el camino del sufrimiento, es capaz de leer los lenguajes que hablan de la injusticia. 
Salud y loca amenidad. Un buen deseo. En síntesis, la locura es, repito, un asunto serio, que ocasionalmente se presta a que se tome humorísticamente, o en broma y hasta con relajo. Como calificativo se aplica equívocamente a un gran número de hechos: anormalidades, estolidez, desadaptación, alucinaciones del individuo - llenas de fantasmas- y delirios culturales, alienación, o estar fuera de sí, ilusiones, manías, demencias, conductas alocadas, identificaciones, imaginación creativa, sandez, demencia, enajenación o extrañamiento, cólera, desvaríos, despropósitos y hasta la negación del otro, del diferente. Ésta última es la perversión, la locura mala, la de las Furias. Las otras vienen de Eros, de las musas, de la ninfa de la juventud y de Pluto, y son positivas, y, cuando no, por lo menos, amenas. Por lo demás, casi nadie pasa la prueba de la realidad que permite al sujeto no confundir los estímulos procedentes del exterior con los internos, o sea, distinguir lo que percibe y fantasea: todos estamos más o menos locos.

Frente a los cuerdos, adaptados y dentro de la norma o pulsión de dominio, cuyo fin es someter al otro, al diferente, la locura de Eros, musas y ninfas es, contra lo que parece, una reserva de salud mental que hace realidad los sueños por los que vale la pena vivir. Ya lo dijo Erasmo: "Todo lo que en la Tierra se hace es obra de locos y para locos, y el que quiera apartarse que siga el ejemplo de Timón [filósofo ateniense famoso por su misantropía]: retirarse a un yermo para gozar libremente de su sabiduría y de la paz de la naturaleza." (p.46). La locura, además, posee el secreto de divertir a hombres y dioses. (p.15) Por lo tanto, no me resta más que desearles salud y persistencia en sus proyectos, señores Locos Amenos

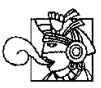

\section{BIBLIOGRAFÍA}

Auerbach, ERich (1979), “Dulcinea encantada” en Mímesis. La representación de la realidad en la literatura occidental, trad. I. Villanueva y E. Ímaz. $2^{\text {a }}$.reimp. México: Fondo de Cultura Económica, (Sección Lengua y Estudios Literarios, p.37).

Basave Fernández del Valle, Agustín (1959), Filosofía del Quijote (un estudio de antropología axiológica). México: Espasa-Calpe, (Col. Austral, 128).

Cervantes Saavedra, Miguel de (1994), El ingenioso hidalgo Don Quijote de la Mancha Iy II, ed. de John Jay Allen, $1^{\text {a }}$ reimp. México: Rei-México (Letras Hispánicas). En México también son accesibles los tres volúmenes de la edición crítica y comentarios de Vicente Gaos, Madrid: Gredos, 1987; otra con prólogo y esquema biográfico de Américo Castro, México: Porrúa, 1962 (Col. "Sepan Cuantos...", 6), y otra más con pról. y vocabulario de Luis Santoyo, México, Orión, 1953.

Dilthey, Wilhelm (1978), Obras. Hombre y mundo en los siglos XVI y XVII, ${ }^{\mathrm{a}}$, imp., trad.

Eugenio Ímaz. México: Fondo de Cultura Económica (Sección Obras de Filosofía).

ERASmo de RotTerdam (1961), Elogio de la locura, trad. F.L. Álvarez, $4^{\mathrm{a}}$ ed. México: Diana. 
Foucault, Michel (1985), "Representar 1. Don Quijote" en Las palabras y las cosas. Arqueología de las ciencias humanas, trad.Elsa Cecilia Frost, $16^{\mathrm{a}}$ ed. México: Siglo XXI Editores (Teoría). También Historia de la locura en la época clásica, trad. Juan José Utrilla. 6 ${ }^{\mathrm{a}}$. reimp. México: Fondo de Cultura Económica, 1982 (Breviarios 191).

Fuentes, Carlos (1976), Cervantes o la crítica de la lectura. México: Cuadernos de Joaquín Mortiz.

González de Mendoza, José María (1970), "Un loco hizo ciento", "Don Rodrigo da de qué hablar", "El libro de Morán", "Rodríguez Marín y El Quijote", "El Quijote y los enquijotados", "Cervantismo descarriado", "Los descubrimientos de Villegas", "Quijotismo pictórico", "Un nuevo cervantista", "El buscarruidos y el buscapié", "Las lucubraciones de Benjumea" y "Cervantes y el Alcázar" en Ensayos selectos. México: Fondo de Cultura Económica (Tezontle).

Gutiérrez Noriega, Carlos (1944), "La contribución de Miguel Cervantes a la psiquiatría" en Cuadernos Americanos (mayo-junio), 82-92.

Ingenieros, José (1961), La psicopatología en el arte, con anotaciones de Aníbal Ponce. Buenos Aires: Editorial Losada (Biblioteca Contemporánea).

LEONARDO DE VINCI (1980), Tratado de la pintura, citado por Rodolfo Mondolfo en "Leonardo, teórico del arte y de la ciencia", Figuras e ideas de la filosofía del Renacimiento. Barcelona: Icaria Editorial.

Llull, Ramon (1986), Obres I, introd. Jordi Gayà Estelrich. Mallorca: Miquel Font Editor. Machado, Antonio (1964), Obras. Poesía y prosa, ed. reunida por Aurora Albornoz y Guillermo de Torre, ensayo prel.de éste. Buenos Aires: Losada. También "Las Meditaciones del Quijote de José Ortega Gasset” en ibid.

Maeztu, Ramiro de (1945), Don Quijote, don Juan y la Celestina. $5^{\text {a }}$ ed. Buenos Aires: Espasa-Calpe (Col. Austral, 31).

Mirandola, Pico della (1982), "Discurso sobre la dignidad del hombre" en El pensamiento renacentista y sus fuentes, comp. Paul Oscar Kristeller, trad. Federico Patán. México: Fondo de Cultura Económica (Sección Obras de Filosofía).

Olmeda, Mauro (1958), El ingenio de Cervantes y la locura del Quijote. México: Atlante. Ortega y Gasset, José (1963), Meditaciones del Quijote e ideas sobre la novela. $7^{\text {a }}$ ed. Madrid: Revista de Occidente.

Platón (1965), Fedro en Diálogos. Hipias Mayor, Ión y Fedro, introd. y trad. Juan García Bacca. México: Universidad Nacional Autónoma de México (Nuestros Clásicos, 29). Unamuno, Miguel de (1988), Vida de Don Quijote y Sancho, ed. Alberto Navarro. Madrid: CÁTEDRA (Letras Hispánicas). 